SCHOLEM (Gershom), Aux origines religieuses du judaïsme laïque. De la mystique aux Lumières

(textes réunis et présentés par Maurice Kriegel), Paris, Carlmann-Lévy, 2000, 316 p. (coll. « Essais Judaïsme »)

Michael Löwy

\title{
CpenEdition
}

Journals

Édition électronique

URL : http://journals.openedition.org/assr/20822

DOI : $10.4000 /$ assr.20822

ISSN : $1777-5825$

Éditeur

Éditions de l'EHESS

Édition imprimée

Date de publication : 1 juin 2001

Pagination : 113-114

ISBN : 2-222-96704-X

ISSN : 0335-5985

Référence électronique

Michael Löwy, «SCHOLEM (Gershom), Aux origines religieuses du judaïsme laïque. De la mystique aux Lumières ", Archives de sciences sociales des religions [En ligne], 114 | avril-juin 2001, document 114.41, mis en ligne le 19 août 2009, consulté le 21 septembre 2020. URL : http://journals.openedition.org/ assr/20822 ; DOI : https://doi.org/10.4000/assr.20822

Ce document a été généré automatiquement le 21 septembre 2020.

(C) Archives de sciences sociales des religions 


\section{SCHOLEM (Gershom), Aux origines religieuses du judaïsme laïque. De la mystique aux Lumières}

(textes réunis et présentés par Maurice Kriegel), Paris, Carlmann-Lévy, 2000, 316 p. (coll. « Essais Judaïsme »)

\section{Michael Löwy}

\section{RÉFÉRENCE}

SCHOLEM (Gershom), Aux origines religieuses du judaïsme laïque. De la mystique aux

Lumières, (textes réunis et présentés par Maurice Kriegel), Paris, Carlmann-Lévy, 2000,

316 p. (coll. « Essais Judaïsme »)

1 Grâce à l'heureuse initiative de M.K., un passionnant ensemble de textes de G.S., le grand historien de la mystique juive, inédits en français ou dispersés dans des publications confidentielles, est rendu disponible au public français.

2 Certains sont des articles de synthèse, comme celui sur la mystique juive et la Kabbale, qui résume les thèmes principaux de son œuvre capitale de 1941, Les grands courants de la mystique juive, en insistant sur le caractère juif originel de ces mouvements, qui ne saurait pas être expliqué par des influences extérieures; ou alors celui sur les manifestations mystiques qui suivent l'expulsion des juifs d'Espagne (1492), dont la principale caractéristique est le retour de l'apocalyptique et du messianisme activiste.

Mais les principaux textes du recueil sont des essais dédiés au sabbatianisme, ce mouvement messianique hérétique des $\mathrm{XVII}^{\mathrm{e}}$ et $\mathrm{XVIII}^{\mathrm{e}}$ siècles redécouvert par G.S. Étudiant les écrits d'Abraham Miguel Cardoso (1627-1706), un des principaux théologiens du mouvement autour de Sabbetai Zevi, il insiste sur son antinomianisme l'aspiration à abroger les préceptes de la loi pour des motifs de foi - gnostique, messianique et révolutionnaire (au sens religieux du mot). 
Deux autres essais sont dédiés au sabbatianisme en Pologne et en particulier à la figure étrange du prophète tardif (XVIII siècle) Jakob Frank, un personnage « satanique » qui fascine et effraye à la fois l'historien G.S., parce qu'il incarne la variante la plus extrême, la plus nihiliste de l'antinomianisme sabbatéen, celle qui, saisie par le "démon de la destruction ", se propose d'« extirper toutes les lois » et d'instaurer une sorte d'« utopie anarchiste » messianique et extravagante.

5 Il me semble que le titre de ce recueil ne correspond pas tout à fait à son contenu. La plupart des textes ne se donnent nullement pour objectif de repérer les origines religieuses/mystiques du judaïsme laïque moderne. Tout au plus esquissent-ils des parallèles entre, par exemple, l'univers de Kafka et celui de la Kabbale, ou entre la doctrine frankiste d'un messie féminin et celle des saint-simoniens, ou encore entre l'idée moderne d'inconscient et celle, chère au hassidisme, d' « intellect primordial ». Il en va de même pour sa tentative surprenante, dans les Dix propositions non historiques sur la Kabbale, de définir cette dernière comme un "matérialisme mystique d'orientation dialectique ». Un des rares exemples qui suggère une sorte de continuité est celui du frankisme, cette révolte mystique/messianique contre toute espèce d'ordre établi, qui semble annoncer, un demi-siècle en avance, la Révolution française. G.S. attire l'attention sur la sympathie des frankistes d'Europe centrale pour la Révolution française et mentionne l'exemple étonnant de Moïse Dobroushka, un neveu de Jakob Frank, converti - suivant l'exemple de son oncle - au christianisme et annobli sous le nom de Franz Thomas von Schönfeld, qui deviendra, sous le nom de Junius Frey, une figure importante du jacobinisme à Strasbourg, avant d'être guillotiné sous la Terreur comme partisan de Danton... Mais même dans ce cas assez exceptionnel, il s'agit, écrit G.S., d'une "extinction du feu messianique » et son remplacement par «l'idée prosaïque du progrès ».

6 Du point de vue des sciences sociales des religions, un des textes les plus intéressants de ce recueil est celui intitulé « Mysticisme et Société : un paradoxe créateur » de 1967, qui semble marquer un tournant dans sa réflexion méthodologique. Tandis que dans ses écrits de jeunesse - comme par exemple l'essai sur Cordovero de 1928 - G.S. n'hésitait pas à écrire que "c'est moins la scène historique d'un courant (...) qui en permettra l'intelligence, que sa scène métaphysique », dans celui-ci il prend le point de vue opposé, en critiquant les études sur le mysticisme qui ont tendance à « séparer les phénomènes religieux de leur contexte social » et à souligner la prétendue différence fondamentale qui les distingue des phénomènes sociaux et historiques. L'expérience mystique, insiste-t-il, n'est pas une pure intériorité - la reine lnnerlichkeit des théologiens protestants ; elle peut avoir une efficacité sociale indiscutable. Lui qui avait toujours manifesté la plus vive méfiance envers la sociologie, fait ici l'éloge des Soziallehren de Troeltsch, comme étude exemplaire - »extrêmement intéressante et féconde" - de sociologie du mysticisme chrétien. Après avoir, dans ses écrits, longuement insisté sur la spécificité et la particularité de la mystique juive, il met l'accent, dans cet essai de 1967, sur les traits communs entre, par exemple, le nihilisme des Frères du Libre Esprit, celui de la secte messianique de David Joris et celui du frankisme polonais; ou encore, sur le caractère révolutionnaire de mouvements qui combinent le mysticisme et le messianisme, comme l'anabaptisme de Thomas Münzer ou le sabbatianisme.

7 Le recueil est complété par quelques poèmes qui nous révèlent le "Scholem secret ", celui qui doute, qui semble avoir perdu la foi, mais qui continue à chercher, avec 
obstination, les rayonnements secrets de la révélation. Deux de ces poèmes sont dédiés à son ami Walter Benjamin : le premier, devenu célèbre, est inspiré par le tableau de Klee, Angelus Novus; le deuxième se réfère au Procès de Kafka, comme manifestation d'une présence négative (le «néant») de la Rédemption. Ces écrits suggèrent l'existence d'une affinité élective entre poésie et mystique. 